\title{
Trypanosoma (Duttonella) vivax: its biology, epidemiology, pathogenesis, and introduction in the New World - A Review
}

\author{
Ana Luiza Alves Rosa Osório/ ${ }^{+}$, Claudio Roberto Madruga ${ }^{1}$, Marc Desquesnes $^{2,3,4}$, \\ Cleber Oliveira Soares ${ }^{1}$, Laura Raquel Rios Ribeiro ${ }^{5}$, Sylvio Celso Gonçalves da Costa ${ }^{6}$
}

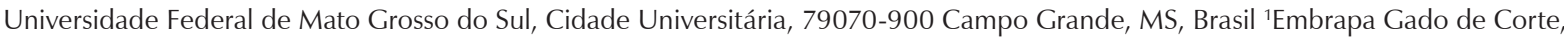
Campo Grande, MS, Brasil ${ }^{2}$ Cirad, UR Trypanosomes, Bangkok, Thaïland ${ }^{3}$ Cirad, UR Trypanosomes, Montpellier, France ${ }^{4}$ Kasetsart University, Bangkok, Thailand ${ }^{5}$ Universidade Católica Dom Bosco, Campo Grande, MS, Brasil ${ }^{6}$ Laboratório de Imunomodulação, Instituto Oswaldo Cruz-Fiocruz, Rio de Janeiro, RJ, Brasil

The biology, epidemiology, pathogenesis, diagnostic techniques, and history of the introduction of Trypanosoma (Duttonella) vivax in the New World are reviewed. The two main immunological responses of trypanosome-infected animals - antibody production and immunodepression - are discussed in the context of how these responses play a role in disease tolerance or susceptibility. Isolation and purification of T. vivax are briefly discussed. The recent reports of bovine trypanosomiasis diagnosed in cattle on farms located in the Pantanal region of the states of Mato Grosso do Sul and Mato Grosso, Brazil, are also discussed.

Key words: mechanical vector - trypanosomiasis - trypanosomes - bovines

Trypanosomiasis is a worldwide disease caused by the species of the genus Trypanosoma, which affects humans, as well as domestic and wild animals. Trypanosoma vivax, Trypanosoma evansi, Trypanosoma equiperdum, Trypanosoma cruzi, and Trypanosoma theileri are of medical and veterinary importance in South America. Apart from T. cruzi, which originated in South America, and T. theileri, which is present worldwide these trypanosome species have been introduced into South America during the last 300 years by humans. T. (Duttonella) vivax Ziemann, 1905, infects a large number of wild and domestic ungulate species; in Africa, its transmission can be either biological (cyclic), with tsetse flies as vectors, or mechanical, via other blood-sucking dipterans (Hoare 1972, Allsopp \& Newton 1985, Gardiner 1989).

The course of a trypanosomal infection varies considerably and depends on both the species of trypanosome and the host involved. Trypanosomiasis is generally characterized by the intermittent presence of parasites in the blood and intermittent fever. Anemia usually develops in infected animals, and this is followed by loss of body condition, reduced productivity and, often, high mortality.

\section{Trypanosoma vivax - systematics and generalities}

The numerous mammal-infecting Trypanosoma species are grouped into the sections Stercoraria and Salivaria. Trypanosomes classified as Stercoraria develop in the digestive tube of vectors and are transmitted through feces. They have a large kinetoplast and multiply in a discontinuous manner in vertebrates, as amastigotes or epimastigotes. Among their counterparts in the section Salivaria, biological transmission occurs by vectors that

Financial support: Fiocruz, Embrapa Gado de Corte, UFMS, CNPq (305388/2005-3)

+Corresponding author: analudmv@nin.ufms.br

Received 28 August 2007

Accepted 24 January 2008 harbor the parasites in their salivary glands; mechanical transmission also occurs. In vertebrates, salivarian trypanosomes multiply in a continuous manner as trypomastigotes (Brener 1979). The increasing complexity of mammal-infecting trypanosomes has required their classification into subgenera, based on phylogenetic hypotheses. For example, for T. vivax, the subgenus Duttonella was introduced (Brener 1979). The main characteristics of Duttonella bloodstream forms are large terminal kinetoplasts situated at a rounded posterior extremity, a medium developed undulating membrane, and a free flagellum (Fig. 1).

In Africa, bloodstream forms of Duttonella trypanosomes exhibit a certain degree of dimorphism. These include club-shaped forms with rounded bodies that are swollen posteriorly and taper abruptly toward the anterior end, and slender forms whose posterior end is also rounded, though not broader than the rest of the body, but tapers gradually toward the anterior end (Hoare 1972). Slender, stumpy, and intermediate forms of African trypanosomes have been observed in the circulation of inoculated animals. During the course of infection, which is marked by peaks of parasitemia and sharp decreases in the number of parasites, the distribution of forms follows a distinctive pattern. During the ascending phase of parasitemia, slender forms predominate, whereas in the descending phase, stumpier ones are more frequent (Ashcroft 1957, Vickerman 1962). The undulating membrane exhibits a medium level of development (more than in $T$. congolense and less than in T. brucei), and a free flagellum is always present. One of the most distinctive traits of these trypanosomes is their large kinetoplast $1.1 \mu \mathrm{m}$ in diameter (Hoare 1938). In the subgenus Duttonella, the kinetoplast is rounded, ranging in shape from circular to elliptic, and is usually terminally positioned. In some forms, however, it can be subterminal or marginal. The large kinetoplast of $T$. vivax is, in itself, a valuable diagnostic trait, as it facilitates identification in blood smears (Hoare 1972). 


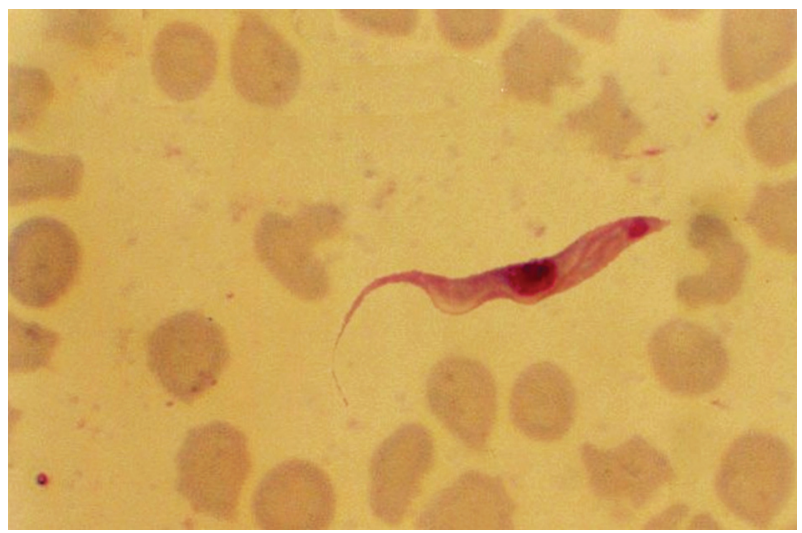

Fig. 1: blood smear of a bovine infected with Trypanosoma vivax from the Aquidauana region of the Pantanal in Mato Grosso do Sul, Brazil. Panoptic staining, 1000x immersion view.

Biometric analysis of several samples of $T$. vivax showed that body length ranges from $18 \mu \mathrm{m}$ to $31 \mu \mathrm{m}$ (including the 3- to 6- $\mu \mathrm{m}$-long free flagellum), with mean lengths ranging from $21 \mu \mathrm{m}$ to $25.4 \mu \mathrm{m}$ (Hoare 1972). Most trypanosomes of this species (90\%) range from $20 \mu \mathrm{m}$ to $26 \mu \mathrm{m}$ in length. Measurements taken from several isolates of T. vivax in South America showed them to be morphologically closer to the slender form from West Africa than to the stumpier isolates found in the eastern regions of the continent (Shaw \& Lainson 1972). Dávila et al. (1997) compared measurements for T. vivax in blood smears of naturally infected bovines from Brazil and Bolivia with those from previous investigations. Statistical analysis of the mean total lengths of parasites obtained from isolates collected from Pantanal de Poconé, in the Brazilian states of Mato Grosso (MT) $(18.73 \mu \mathrm{m})$ (Silva et al. 1995), and Pará (PA) (22.77 $\mu \mathrm{m})$ (Shaw \& Lainson 1972), and from Santa Cruz, Bolivia $(15.86 \mu \mathrm{m})$ revealed significant differences among all three isolates. Despite these differences, however, similarities were found in the subterminal positioning of the kinetoplast for isolates from PA and from Bolivia. Biometric analysis of T. vivax cattle samples from the Poconé yielded the following dimensions: total length of $22.02 \pm 3.32 \mu \mathrm{m}$, a distance from kinetoplast to posterior end of $1.05 \pm 0.56 \mu \mathrm{m}$, a kinetoplast to nucleus length of $6.09 \pm 1.34 \mu \mathrm{m}$, a posterior end to nucleus distance of $7.14 \pm 1.39 \mu \mathrm{m}$, a nucleus to anterior end distance of $6.68 \pm 1.53 \mu \mathrm{m}$, a free flagellum length of $8.35 \pm 1.80 \mu \mathrm{m}$, a long diameter of nucleus of $2.77 \pm 0.58 \mu \mathrm{m}$, and a short diameter of nucleus of $1.79 \pm$ $0.40 \mu \mathrm{m}$ (CR Madruga et al., unpublished observations). Morphometric characterization of a $T$. vivax isolates from the Aquidauana region of the Pantanal in Mato Grosso do Sul (PMS) showed the dimensions of these parasites to be significantly $(\mathrm{p}<0.05)$ greater than those of isolates from cattle from Poconé. Indeed, they had a longer body $(22.11 \pm 0.88 \mu \mathrm{m})$, a greater distance from the posterior end to the nucleus $(8.45 \pm 0.42 \mu \mathrm{m})$, and a larger, more elongated nucleus (long diameter $3.42 \pm 0.26 \mu \mathrm{m}$, short diameter $0.42 \pm 0.08 \mu \mathrm{m}$ ) (Osório 2002). The parasites described by Desquesnes (1997b) in isolates from French
Guyana and Venezuela are most often long (20-26 $\mu \mathrm{m})$, but sometimes short (15-16 $\mu \mathrm{m})$, with mean sizes of $20.3 \mu \mathrm{m}$ and $21.5 \mu \mathrm{m}$, respectively. When cultivated in calves or sheep, they sometimes appear pleomorphic, but the size of the kinetoplast remains constant (Desquesnes 2004).

Finally, it must be emphasized that in fresh microscopic examinations, T. vivax is characterized by its capacity to quickly cross the microscope field of vision while other parasites move around. Its intermediate undulating membrane distinguishes it from large membrane ones exhibited by trypanozoan parasites such as T. evansi which can trap light creating typical "pockets of light". Among other characteristics, such as the size of the parasite, the round posterior extremity of $T$. vivax can also be distinguished from athe very long, thin and rigid posterior of T. theileri (Desquesnes 2004).

\section{Transmission}

In Africa, T. vivax is a heteroxenous parasite present in regions populated by tsetse flies, genus Glossina. The parasite develops in the proboscis of this invertebrate host, where trypomastigotes evolve to epimastigotes. This is a crucial phase, as it leads to the development of metacyclic trypomastigotes, the only form capable of infecting vertebrate hosts through fly bites. Glossina spp. is the only vector in which T. vivax is able to multiply and remain in the infective phase throughout the insect's life. Outside tsetse fly areas, such as in South America, the parasite is carried by other hematophagous flies where transmission is noncyclical. Thus, the parasites are mechanically transmitted across vertebrate hosts, with no growth or multiplication in the insects (Hoare 1972, Molyneux \& Ashford 1983, Gardiner 1989). In these cases, the fly feeds on more than one animal before repletion and remains infective for only a short time. Nevertheless, mechanical transmission of T. vivax by hematophagous flies other than tsetse has enabled the parasite to become established in South America and Mauritius. In South America, T. vivax has been disseminated by horse flies (Tabanidae) (Hoare 1972) and stable flies (Stomoxys spp.) (Levine 1973). Mechanical transmission across cows has been experimentally demonstrated for the tabanids Cryptotylus unicolor (Ferenc et al. 1988 apud Dwinger \& Hall 2000), and Tabanus importunus (Raymond 1990) in French Guiana, and for Tabanus nebulosus in Colombia (Otte \& Abuabara 1991). Although it has been proposed that the parasite might be cyclically transmitted in South America by an unknown vector other than Glossina (Wells 1972), no evidence is available to support this hypothesis. Mechanical transmission of African isolates of $T$. vivax was recently demonstrated in experimental conditions with tabanids (Desquesnes \& Dia 2003, 2004). These data suggest that, in Africa, mechanical and cyclical transmission co-exist in the field. However, only mechanical transmission can explain the permanent presence of $T$. vivax outside the tsetse belt. Some authors have also mentioned mosquitoes as potential vectors for T. vivax in Venezuela and Cuba (RuizMartinez 1971, Cordoves et al. 1982). Experimentally, T.vivax may also be transmitted by "syringe passage" of infective blood (Van den Bossche et al. 2000). 
The degree of parasitemia in mammal hosts affects the rate of mechanical transmission of T. vivax (Roberts et al. 1989). A direct link between the level of parasitemia and the success of transmission can even be drawn (Desquesnes et al. 2005). Another factor associated with this rate is the presence of tabanids, which have larger populations in swampy areas. Otte et al. (1994) found a significant temporal relationship between the feeding activity of tabanids and the incidence of $T$. vivax, providing evidence for the role played by these insects in T. vivax infection. Based on the level of parasitemia and the biting insect frequency, a mathematical model for the mechanical transmission of $T$. vivax is now under development (Desquesnes et al. 2005).

In Latin America, T. vivax transplacental transmission and the manifestation of perinatal Trypanosomiasis seem to be of epidemiological relevance. Circumstantial evidence gathered by Betancourt (1978, apud Dwinger \& Hall 2000) from Venezuela, was later confirmed under experimental conditions in the same country (Meléndez et al. 1993), as well as during outbreaks of the infection in the PMS, Brazil (NS Barbosa Jr et al., unpublished observations). In Africa, in contrast, transplacental transmission is uncommon (Ogwu \& Nuru 1981), and therefore of low relevance in the epidemiology of the disease (Dwinger \& Hall 2000).

\section{Hosts and distribution}

In Africa, several species of ungulates are hosts for $T$. vivax, including not only domestic animals such as bovines, ovines, and caprines, but also equids and camelids, to which the parasite is pathogenic, and wild animals, such as several species of antelope, to which it is innocuous (Hoare 1972). In South America, T. vivax occurs not only in bovines and bubalines (Shaw \& Lainson 1972) in areas subject to flooding, but it also infects capybaras (Fernandez 1931) and wild ungulates such as the whitetailed deer, or cariacou (Odocoileus gymnotis) (Fiasson et al. 1948). Although wild ungulates may serve as reservoirs for this hematozoan (Fernandez 1931, Fiasson et al. 1948), no conclusive proof has been found that the cervid is an epidemiologically important reservoir for $T$. vivax infection in bovines (Desquesnes \& Gardiner 1993). Unlike in Africa, T. vivax has not been observed in American horses (Ruiz-Martinez 1971).

In tropical Africa, T. vivax is found in an extensive area that is a habitat for flies of the genus Glossina. Outside the tsetse area, the parasite is also found in most of the western, eastern, and central regions of South Africa (Hoare 1972). It is generally thought that $T$. vivax was introduced into the New World at around 1830, when Zebu cattle from Senegal were exported to French Guiana and the Antilles (Lerger \& Vienne 1919, Fabre \& Bernard 1926, Carougeau 1929, Curasson 1943). However, such introduction might have occurred in 1733 directly from the African continent and Cap Green Islands, as well as via the Caribbean islands (Maillard \& Maillard 1998). Later, the parasite was found in Panama (Johnson 1941), Suriname, Guyana (Nieschulz 1939 apud Hoare 1972), Venezuela (Tejera 1920, Fernandez 1931), and Colombia (Plata 1931a), where the cattle-infecting disease, locally known as "secadera", was of considerable economic concern (Kubes 1944 apud Hoare 1972). However, it is not possible to identify dates and means of introduction in these countries (Desquesnes 2004).

In Brazil, the occurrence of T. vivax in bovines was first recorded in the Amazon state of PA, by Bulhosa (1946, apud Shaw \& Lainson 1972), and later identified in buffaloes (Bubalus bubalis) in flooded areas of the same state near Belém (Shaw \& Lainson 1972). In the late 1970s, the protozoan was identified in bovines and ovines in the states of PA and Amapá (Pereira \& Abreu 1979); in buffaloes, it was found in Amapá (CL Massard et al., unpublished observations) and in the municipality of Belém, PA (Serra-Freire et al. 1980, unpublished observations). In MT, the disease was diagnosed in cattle on farms located in the Poconé region of the Pantanal (Silva et al. 1995, 1996). In the PMS, bovine Trypanosomiasis was identified the municipalities of Miranda (Paiva et al. 1997) and Aquidauana (NS Barbosa Jr et al. 2001, unpublished observations).

\section{Genetic diversity}

The genetic diversity of T. vivax has been well-documented in Africa (Majiwa et al. 1993), but data for Latin America remain limited. In Colombia, isoenzymatic and karyotype studies carried out by Dirie et al. (1993a) showed strong relationships with West African strains; however, immunolysis tests revealed full cross protection amongst Colombian stocks, but only partial protection with West African stocks. Similarly, partial cross protection observed between T. vivax stocks from French Guiana and Venezuela proved that they are closely related, but belong to different serodemes (Desquesnes 2004). Dirie et al. (1993a) demonstrated that Colombian strains are close to West African strains, although they could distinguish all isolates studied. Using the same primers, Desquesnes (2004) obtained almost identical fingerprints with one Venezuelan and three Guianan isolates. These observations favored a moderated genetic diversity of the Colombian, Venezuelan and Guianan isolates studied. In Brazil, studies on polymorphisms lead by Madruga et al. (1999) showed that bovine T. vivax samples from Pantanal of Poconé, MT, possess the gene that codes for the soluble antigen for T. vivax and that its genomic organization is similar to that of West African $T$. vivax. The sequence of the spliced-leader gene repeat of a Brazilian T. vivax stock from cattle showed high similarity to sequences of West African T. vivax in both intron and intergenic sequences. A T. vivax-specific diagnostic polymerase chain reaction (PCR) assay based on splicedleader gene intergenic sequences amplified DNA from $T$. vivax stocks from South America (Brazil, Bolivia, and Colombia) and West Africa (Ventura et al. 2001). Cortez et al. (2006) compared South American isolates (Brazil and Venezuela) with West- and East African T. vivax isolates. Phylogeny using ribosomal sequences positioned all $T$. vivax isolates tightly together on the periphery of the clade containing all Salivarian trypanosomes. The same branching of isolates within the T. vivax clade was observed in all inferred phylogenies using different data sets of sequences. T. vivax from Brazil, Venezuela, and 
West Africa (Nigeria), corroborating the West African origin of South American T. vivax, whereas a large genetic distance separated these isolates from the East African isolate (Kenya) analyzed. Brazilian isolates from both asymptomatic cattle and those showing distinct pathology were highly homogeneous. Genetic polymorphism has been demonstrated between regions of the Pantanal Brazilian isolates (Osório 2002). Two T. vivax isolates collected from Pantanal de Poconé, MT, and Aquidauana, PMS, were submitted for genetic analysis. Genetic characterization by PCR using random oligonucleotides as primers (RAPD) and PCR based on repeated extragenic palindromic sequences (REP-PCR) and repeated intergenic sequences (ERIC-PCR) revealed polymorphisms among the isolates, but with coefficients of similarity of 0.69 , indicating high genetic proximity. These results demonstrate for the first time that the REP and ERIC sequences are also present in this trypanosome species.

From the knowledge acquired to date, it appears that the genetic diversity of Latin American T. vivax isolates is much lower than that of African strains (Desquesnes 2004), most probably due to the lack of genetic recombination, which occurs only in the intermediate tsetse host (Gibson 1995). These observations help explain the ability of South American cattle populations to temporarily control the infection while such control is not possible in Africa.

\section{Economic impact}

In Africa, losses caused by bovine trypanosomiasis have been estimated at roughly five million dollars annually if declines in beef production are taken into account, not to mention losses in milk production and secondary products, such as leather (ILRAD 1989). So far, the impact of bovine trypanosomiasis in Latin America has not been satisfactorily estimated, although it is thought to rank third among parasitic diseases in economic importance, after tickborne diseases and fasciolosis in Colombia (ICA 1980, Wells et al. 1982). Betancourt \& Wells (1979) calculated losses from an outbreak among dairy cattle in Colombia to average US\$ 56.50 per animal. In French Guyana, Desquesnes (2004) estimated that an outbreak of trypanosomiasis in beef cattle cost the equivalent of 3.3\% live weight per animal; which can be split into $30 €$ of weight loss and $3 €$ of treatment per head. Otte et al. (1994) suggested that even inapparent losses from subclinical infections might be sizeable. The financial impact of T. vivax bovine trypanosomiasis occurring in Brazilian Pantanal and Bolivian lowlands has been estimated at US\$ 15 per animal ( $4 \%$ of the total value of each head of cattle). Without treatment, this cost would soar to as much as US\$ 64 per animal, or $17 \%$ of the total value (Seidl et al. 1999). In Brazil, the cost of treatment with isometamidium chloride (Trypamidium $\AA$ ) is estimated at US\$ 37.80/animal/year for the prevention of $T$. vivax infection in high richrisk areas in the Pantanal region ( $\mathrm{P}$ Stevenson 1995, unpublished observations).

\section{Course of infection}

The mechanism of inoculation described in Africa (Emery et al. 1980) has not been observed in Latin America and is most probably linked with the inoculation of trypanosomes by tsetse flies (Desquesnes 2004).
The prepatent period of infection by T. vivax is variable, depending on the host and the parasite isolate. In sheep and goats, the incubation period lasts from four to 12 days (Hoof et al. 1948). In bovines, it ranges from nine to 14 days for virulent isolates, and from nine to 59 days in infections with less pathogenic isolates (Hoare 1972). T. vivax parasitemias exhibit irregular fluctuations, with some cases occurring at high levels in the morning and at lower levels in the afternoon on the same day. As a rule, however, an initial period of parasitemia will last for several months before trypanosomes become undetectable in the blood. After that phase, periods of recurrence take place (Hoof et al. 1948).

With African strains, the course of trypanosomiasis caused by $T$. vivax has been studied in bovines, which comprise the main hosts of the parasite. The pathogenicity of the infection varies with host resistance and the parasite isolate. Virulence seems to be a stable property of each given isolate, as the disease exhibits acute features of short duration in some regions, whereas in others, it follows a chronic course (Hoare 1972). In zebus, for instance, infection can lead to a $100 \%$ mortality rate three to four months after exposure to tsetse flies, as has occurred in Nigeria (Hoare 1972). In other areas, however, such as the Congo (Hoof et al. 1948), the disease can have sub-acute features in calves for two months, after which trypanosomes disappear from the bloodstream and recovery is spontaneous.

At the population level, the course of the infection evolves over time. In French Guiana, in cattle, Leger and Vienne (1919) described very strong clinical signs including fever, anemia, edema, abortion, weight loss, posterior paresia, and a mortality rate close to $50 \%$. Seventy years later, in experimental conditions, Camus and Martrenchar (1990) observed milder symptoms in local breeds; however, very acute signs were described later by Desquesnes (1997b) in cattle recently imported from France. Similarly, in Colombia, the initial outbreaks were very acute, but the intensity of the clinical signs decreased in subsequent epizootic outbreaks (Virviescas 1932, Wells et al. 1982).

Evidence is available suggesting that the level of virulence of $T$. vivax isolates is associated with the biological vector species. Thus, the isolate transmitted by Glossina pallipides in the central region of Kenya causes acute disease that leads to death in roughly one month in $70 \%$ of the cattle infected, while an isolate transmitted by Glossina fuscipes in the Kenyan province of Nyanza causes chronic infection followed by death 100 to 160 days after the initial parasitemia (Hoare 1972).

In other domestic animals, the disease caused by $T$. vivax can also exhibit visible variation. It can be acute or chronic, with mortality rates of $70 \%$ and $12 \%$ in sheep and goats, respectively (Hoof et al. 1948), although moderate infection is not uncommon (Hoare 1972).

With Latin American strains, the infection studied under experimental conditions in 15 two year-old creole ovines (Desquesnes 1997b) showed repatent periods of five to 20 days, with early peaks of parasitemia being very often high, accompanied by clinical signs. Depending 
on the cases, with the same isolate, recovery occurred naturally within 3-4 months (Fig. 2) or requiresd treatment to avoid the death, showing the strong impact of individual host immune capacities.

Relapse of the parasites in blood and clinical signs could even be induced by food restriction in sheep experimentally infected (Desquesnes 2004). Intercurrent diseases are also known to be predisposing factors for T. vivax infection in bovines (Desquesnes \& Gardiner 1993).

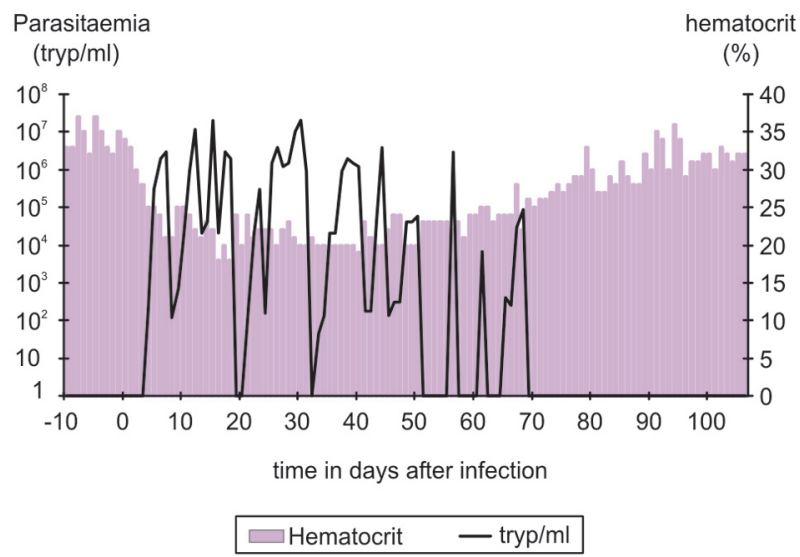

Fig. 2: parasitaemic and haematocrit profiles of a sheep experimentally infected with Trypanosoma vivax from French Guiana.

\section{Pathogenesis and symptoms}

Certain African isolates of T. vivax can cause acute disease accompanied by hemorrhagic syndrome (Mwongela et al. 1981, Roeder et al. 1984). Typical features of these infections include high, persistent parasitemia, fever, very pronounced anemia, and generalized visceral and mucosal hemorrhage, particularly in the gastrointestinal tract. In the field, the disease affecting adult cattle can be severe enough to lead to death or miscarriage, even before diagnosis is reached and treatment can be started (Mwongela et al. 1981). However, such a feature has never been described in Latin America (Desquesnes 2004).

Severe acute anemia and thrombocytopenia are associated with the onset of parasitemia (ILRAD 1989, Assoku \& Gardiner 1989). Widespread phagocytosis of blood cells, such as erythrocytes and platelets, by macrophages invading bone marrow sinusoids is seen (Murray \& Dexter 1988, Gardiner 1989). Anemia is the chief sign of bovine trypanosomiasis, and its persistence is responsible for congestive heart failure (Sannusi 1979 apud Gardiner 1989). These are the main causes of death in the field (Murray et al. 1979).

Evidence is available suggesting that hemolysis is immunomediated. Anemia might result from the deposition of immunocomplexes on the erythrocyte surface, triggering erythrophagocytosis (Murray \& Dexter 1988, Andrianarivo et al. 1995). Similarly, nonspecific phagocytosis of erythrocytes by means of a hyperactivated phagocytic system or specific phagocytosis of damaged cells may contribute to anemia (Taylor 1998).
In South America, the disease caused by $T$. vivax in adult cattle is accompanied by fever, parasitemia, anemia, lethargy, loss of physical function, decrease in milk yield, miscarriage, and death (Losos \& Ikede 1972). Lacrimation, subcutaneous edema of the head, epistaxis, and diarrhea have been reported in cattle that die after experimental infection (Vohradsky 1971). Experimental studies have been performed in bovines, ovines, caprines, swine, and equines using T. vivax isolated from a buffalo from the Northern Brazilian state of Amapá. Daily blood smears revealed fluctuating parasitemia in most of the animals inoculated, particularly ruminants. The most frequent clinical picture included intermittent fever, lacrimation, nose discharge, anemia, edema, and progressive weight loss (Souza 1980).

Regarding the fertility of bovines and ovines, multiple abnormalities have been identified in the sperm morphology of experimentally inoculated animals (Sekoni et al. 1990, Sekoni 1993). Abortion has been recorded in experimentally infected sheep (Desquesnes 2004). Outbreaks of miscarriage have been reported during trypanosomiasis due to T. vivax (Bawa et al. 2000), though the parasite has not been found in fetal blood or in amniotic fluid (Losos \& Ikede 1972). Under experimental conditions, however, T. vivax was found in a blood smear from a calf hours after birth (Melendéz et al. 1993). While evaluating an outbreak of trypanosomiasis, NS Barbosa Jr et al. (unpublished observations), using blood smears and PCR, detected T. vivax in the blood of a calf that died soon after birth. The low sensitivity of the parasitological method adopted may account for the differences in the results.

Otte et al. (1994) showed that the disease can become subclinical in endemic settings, though it still causes sizeable losses in production. Animals recovering from the disease can become reservoirs, with low or even undetectable blood levels of the parasite (Plata 1931b). In the aparasitemic phases, trypanosomes can be found extravascularly, in lymph nodes (Hoare 1972), eyes (in the choroid plexus and aqueous humor) (Whitelaw et al. 1988), and cerebrospinal fluid (Tuntasuvan et al. 1997). Occult infections can be reactivated by stress. As a consequence, the infectious agent can spread quickly when cattle movement along commercial routes is combined with the availability of potential vectors (Dwinger \& Hall 2000). Given the possibility of extravascular location, $T$. vivax can directly damage tissues, as when ocular tissues are involved, with ensuing keratitis (Hoare 1972), or when the cardiac muscle exhibits lesions characterized by hemorrhage and mononuclear infiltration (Van Den Ingh \& Neijs-Baker 1979, Valli \& Forsberg 1979, Kimeto et al. 1990).

In outbreaks of $T$. vivax trypanosomiasis affecting cattle in the Pantanal, fever, lacrimation, edema, keratitis, and weight loss have been seen in the acute phase of the infection (Silva et al. 1995, 1996). However, Paiva et al. (unpublished observations), in a follow-up of clinical cases (experimentally reproduced) and during outbreaks of the disease in the PMS, failed to detect the clinical signs described above, but suggest that the parasite should not be overlooked, given the possibility of its expression when associated with other agents or under poor management conditions. 
In Brazil there are no studies comparing the pathology of Brazilian T. vivax isolates, however genetic polymorphisms have been demonstrated among Pantanal isolates. Outbreaks with severe disease manifestations have been described in the Pantanal lowlands associated with high temperature, lethargy, weakness (Fig. 3A), anemia, diarrhea (Fig. 3B), abortion, and mortality (Osório 2002). An outbreak of trypanosomiasis by T. vivax is reported in the semiarid area of Paraíba, Northeastern Brazil. Sixty-four cows out of 130 were affected; 11 died and the others recovered after treatment with diminazene aceturate. Affected animals exhibited fever, anemia, weight loss, hypoglycemia, increased serum levels of aspartate aminotransferase and, in nine cows, nervous signs (Batista et al. 2007).

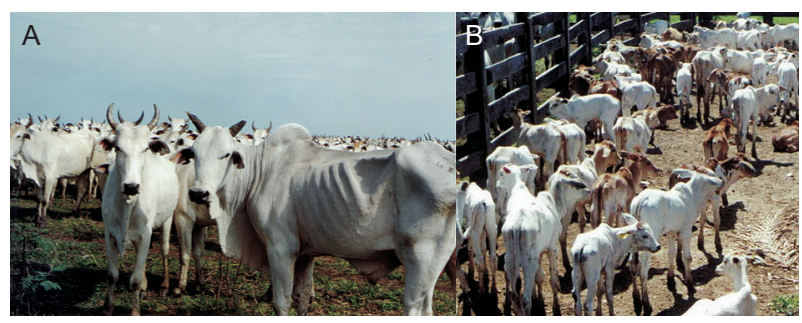

Fig. 3: accute phase during Trypanosoma vivax Trypanosomiasis outbreak in cattle from Aquidauana region of the Pantanal in Mato Grosso do Sul, Brazil. A: weight loss; B: diarrhea in year-old calves.

\section{Laboratorial aspects of trypanosomiasis by T. vivax}

In bovine trypanosomiasis, anemia is described as normochromic-normocytic, with a tendency to be normochromic-macrocytic. Macrocytosis is due to erythrogenesis that takes place two weeks after the onset of infection, at which time, immature erythrocytes are released into the bloodstream (Saror 1979, Anosa \& Isoun 1980). Esievo \& Saror (1983), upon experimentally infecting zebu cattle, observed the development of leukopenia with simultaneous lymphopenia and neutropenia, suggesting that increases in parasite antigens and neuraminidase are concurrent with leukocyte changes.

Upon reproducing the disease in cattle with a $T$. vivax isolate from Miranda, PMS, Paiva et al. (unpublished observations) found that red blood cell values remained within normal parameters. Decreases were found, however, in the counts taken over the first 16 days post-inoculation (dpi), with subsequent increases and stabilization. Lymphocytic leukocytosis, eosinopenia, and increases in the concentrations of total plasma proteins were also observed. Fibrinogen levels decreased only once, at 42 dpi. Also under experimental conditions, Schenk et al. (2001) found a decrease only in hematocrit values upon inoculating cattle with a $T$. vivax isolate from the region of Poconé, MT. Anemia and leukopenia were found in infected cattle from Bolivia and the Brazilian Pantanal. The animals had hypochromic-macrocytic anemia. Leukocyte changes included lymphocytosis, relative monocytosis, and decreased neutrophil count (Silva et al. 1999).

\section{Control of infection by immune response}

The antigen-antibody reaction triggers immune response mechanisms that promote host resistance to $T$. vivax infection. One such mechanism involves the formation of a lysis complex that annihilates the parasite by activating the complement system. Additional mechanisms include phagocytosis, rendered more efficient by antibody opsonization, and antibody-dependent cytotoxicity (MacAskill et al. 1980).

As a result of their co-evolution, trypanosomes are often nonpathogenic in wild animals (Mulla \& Rickman 1988). Similarly, some breeds of cattle remain relatively healthy and productive in areas where tsetse-transmitted trypanosomiasis occurs (Murray et al. 1979). Although these animals become infected, they are more resistant to the pathogenic consequences of infection than other breeds. Naturally disease-resistant cattle are known as trypanotolerant and include Bos taurus N'Dama, Muturu, and Dahomey, found mainly in West Africa. In areas where there is a high risk of infection, trypanotolerant cattle continue to grow and reproduce, whereas zebu (Bos indicus) cattle become cachectic, weak, prone to abortion, and frequently die (Murray et al. 1982). N'Dama cattle are more resistant to T. congolense (Paling et al. 1991), T. brucei (Murray et al. 1979), and thanthe West African isolates of T. vivax than Boran cattle. However, both breeds of cattle are highly susceptible to infection with hemorrhagic strains of T. vivax (Williams et al. 1992).

Nonimmunological factors, as well as factors associated with $T$. vivax, such as sialidase, a neuraminidase that hydrolyzes sialic acid in vitro, may have a role in the destruction of host erythrocytes (Esievo et al. 1982). Sialic acid is an important component of the erythrocyte surface membrane. Its removal from the erythrocyte surface is normally an age-dependent process and leads to removal of aged cells through phagocytosis. Esievo et al. (1982) reported a decline in the amount of sialic acid on the erythrocyte surface in cattle infected with $T$. vivax leads to anemia because of the process described above. Esievo et al. $(1986,1990)$ showed that in N'Dama cattle, concentrations of sialic acid on the erythrocyte surface are higher than in zebu cattle. Because the amount of sialidase and its subsequent hydrolysis is proportional to the concentration of trypanosomes, it has been hypothesized that N'Dama cattle might require a larger number of trypanosomes to reach the same level of erythrocyte damage. This might explain why in N'Dama animals the early stages of anemia are more efficiently controlled, even though the first peak of parasitemia is approximately the same for N'Dama and Boran animals (Taylor 1998).

Also, serum levels of complement in T. vivax- and T. congolense-susceptible cattle are decreased, which results in impaired phagocytosis and impaired immunoregulatory activity of the complement. As noted earlier, complement and complement receptors (CRs) on the surface of follicular dendritic cells play a role in the production of $\operatorname{IgG}$ and the formation of memory cells (Nielsen et al. 1978, Tabel et al. 1980).

Cattle susceptibility to trypanosomiasis is associated with an inability to control parasitemia and the pathology, primarily reflected as anemia. These features are 
compounded by a decrease in complement components (Authié \& Pobel 1990). In addition, bovines exhibit an undesirable humoral response, due to the production of polyspecific antibodies, poor response of memory B cells, and an inability to switch the IgM isotype into an IgG isotype (Paling et al. 1991, Taylor et al. 1996a, b). These defects might pose difficulties for an effective control of parasitemia, neutralization of trypanosome factors, or clearance of immunocomplexes (Taylor 1998).

\section{Immunosuppression}

Host immunosuppression is a well-known feature of bovine, human, and murine trypanosomiasis (Nantulya et al. 1982, Flynn \& Sileghem 1991, Sileghem et al. 1991, De Baetselier et al. 2001). In some cases, suppression is specific, involving only the host response to the parasite; in others, generalized suppression occurs in the infected animals, marked by a decrease in $\mathrm{T}$ cell proliferation and cytokine production (Taylor 1998, Taylor \& Mertens 1999). This is why the immunological response to various heterologous and nonparasitic antigens is weak in cows (Nantulya et al. 1982, Sileghem et al. 1994a). The occurrence of secondary bacterial infections in T. vivaxinfected ruminants lends support to the features described above (Losos \& Ikede 1972, Anosa \& Isoun 1980). As noted earlier, immunosuppression was first identified based on increased susceptibility of trypanosome hosts to secondary infections and has been further studied in this light. This is a relevant phenomenon, as cattle infected in the field often die of opportunistic infections. Disease-associated suppression also affects host immune response to trypanosomes. Nonetheless, the role of suppression in parasite control is not clear (Sileghem et al. 1994a).

Several studies have been conducted on the humoral response to parasite antigens. Williams et al. (1996) and Taylor et al. (1996b) found that trypanosome-susceptible cattle produce lower levels of IgG against trypanosomespecific antigens than do tolerant cattle. Two hypotheses have been generated to try to explain the decreased antibodies titers observed in infected cattle. The first of these is that the mechanism involves the increased catabolism of serum immunoglobulins (Nielsen et al. 1978) or antigenic competition (Nantulya et al. 1982). It has also been proposed that macrophages play a central role in initiating immunosuppression by interacting with the parasite (Sileghem et al. 1994b).

\section{Evolution of immunity at the population level}

In Africa, the transmission of several Trypanosoma species (T. vivax, T. congolense and T. brucei) by tsetse flies, in which the parasites multiply and undergo genetic recombination, leads to a high incidence of infections with high infective doses and a high genetic diversity of parasites. In such conditions, a large portion of the cattle population is unable to control the infection (Desquesnes \& Dia 2003). In America, the transmission of a single Trypanosoma species (T. vivax) (setting aside the case of T. evansi, which seems to have very low, if any, prevalence in cattle) with low genetic diversity by mechanical vectors that transmit a small number of parasites for a very short time leads to natural control of the infection after some time in most of the hosts (Desquesnes 2004). For comparison of these epidemiological features, Fig. 4 shows a theoretical model of trends in parasitological (Woo or Murray test for example) and serological prevalence (antibody detection of IgG by enzyme-linked immunosorbent assay, ELISA, for example) of T. vivax in cattle populations that are exposed to mechanical vectors (Fig. 4A) compared to cyclical vectors (Fig. 4B), as described below.

In areas where transmission of $T$. vivax is strictly mechanical, such as in Latin America, bovine trypanosomiasis occurs in the form of periodic multiple epizootic outbreaks against a subclinical enzootic background. Because mechanical transmission is unpredictable, the epidemiological situations are unstable. Following an 'epizootic wave' (Fig. 4A, phase 1), infections are gradually eliminated by self-curing and treatment (initially,

\section{A}

\section{prevalences (\%)}

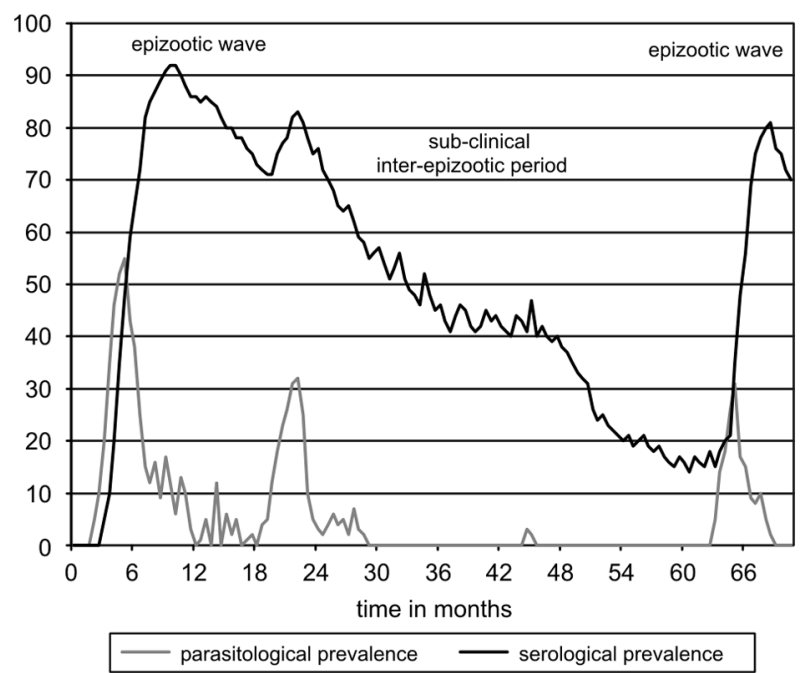

B

prevalences (\%)

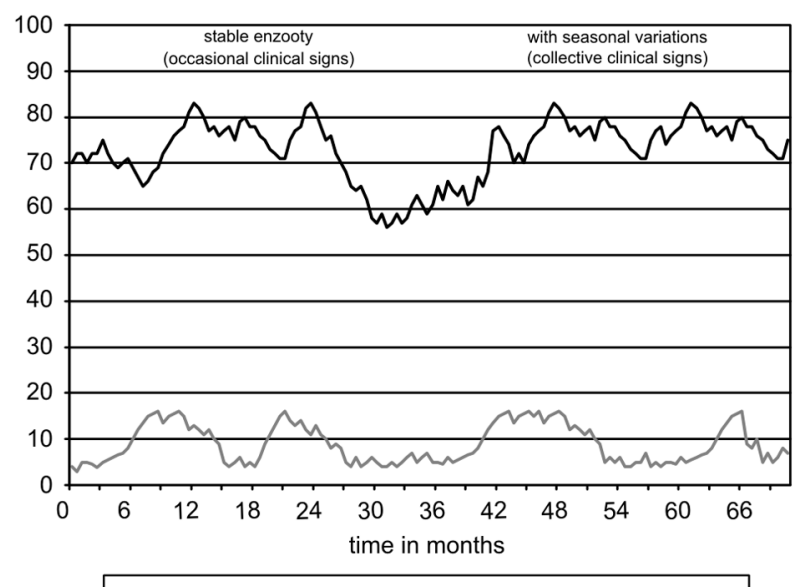

parasitological prevalence $\quad$ serological prevalence

Fig. 4: model of trends in parasitological and serological prevalences of Trypanosoma vivax in cattle populations that are exposed to (A) mechanical and (B) cyclical vectors. 
treatments against trypanosomiasis in the case of an epizootic outbreak, and later possibly against babesioses). During this period, which couldcan be referred to as the 'inter-epizootic period' (Fig. 4A, phase 2), concomitant immunity becomes established and maintains very low parasitemia. It is very difficult to detect parasites in the bloodstream of animals (parasitological prevalence is nil), but the presence of the parasite in the population is nonetheless confirmed by the non-insignificant prevalence of antibodies over several years (Fig. 4A, phase 2). After several years, most of the population becomes susceptible (seroprevalence down to $20 \%-30 \%$ ), and when other circumstances arise (seasonal immunosuppression that leads to high parasitemias in a number of carriers and vector proliferation) another 'epizootic outbreak' (Fig. 4A, phase 3) is triggered. This phenomenon, which we can refer to as 'an epidemiological seesaw' is typical of mechanically transmitted bovine trypanosomiasis and has been observed in several South American countries (French Guiana, Colombia, and Venezuela) (Desquesnes 1997b). The trypanosomes that trigger epizootic outbreaks are either already present in the herds (aparasitemic resurgence following stress, namely drought and hyperabundance of hæmatophagous insects) or are brought in by the introduction of infected animals. That is why the disease often occurs in the form of multiple outbreaks (concomitant resurgences under the effect of climate, or dissemination of the disease by a batch of carrier animals that are sold individually to different farmers). This alternation between 'epizootic clinical' and 'inter-epizootic subclinical' phases is characterized by long silent periods during which the parasite is not visible followed by very widespread clinical explosions (Desquesnes 2004).

For mechanical transmission to be achieved, a number of conditions must be fulfilled simultaneously (high parasitemia in carriers, abundance of vectors, availability of recipients), and hence, its probability is relatively low. This and explains why transmission is not observed every year. However, when these conditions are fulfilled, the incidence of mechanically transmitted infections is very high (>70\% per month) and triggers explosive outbreaks. Furthermore, mostly unchallenged animals all express the disease making it very ostensible (Desquesnes 2004).

In areas in Africa where the disease is cyclically transmitted by Glossina, these cycles do not arise and trypanosomiasis is a permanent blight that is constantly detectable. Although the incidence of infection and parasitological, serological, and clinical prevalence varies on a seasonal basis (Fig. 4B), there are never any wholly silent periods as in America because Glossina are permanent carriers of several of the parasite species, some of which are highly pathogenic ( $T$. congolense savanna type). Furthermore, mechanical transmission also occurs in areas infested by Glossina because these areas are also attractive to ecologically less demanding hæmatophagous insects. In addition, Glossina themselves are mechanical vectors. Mechanical transmission therefore occurs in addition to cyclical transmission and contributes to the intensification of $T$. vivax, allowing for the maintenance of and a high prevalence of infection for this particular species (Desquesnes \& Dia 2003, 2004).

\section{Diagnosis and differential diagnosis}

T. vivax infection can be diagnosed by parasitologi$\mathrm{cal}$, immunological, and molecular methods. The hematocrit centrifuge technique (Woo 1970, Betancourt \& Julio 1979 ) is one of the most widely used among the parasitological methods, in which motile trypanosomes can be viewed between the leukocyte layer and the plasma. The technique allows for the detection of trypanosomes six to ten days before they are detected in a fresh drop or from thick smears (Molyneux 1975). Despite its ease of use, Woo's technique exhibits low sensitivity when applied during the chronic phase of the disease, and sensitivity decreases considerably when the parasitemia is below 200 parasites $/ \mathrm{ml}$. (Desquesnes \& Tresse 1996a).

A T. vivax soluble-antigen capture ELISA developed by Nantulya and Lindqvist (1989) looked promising for the detection of active infections, however, the evaluation of the test in Latin America demonstrated a lack of specificity and sensitivity (Desquesnes 1995). Further re-evaluation was then suggested in Africa and led the scientific community to abandon these reagents (Morzaria et al. 1996).

Serological techniques such as immunofluorescence (IF) and ELISA can be used for direct and indirect diagnosis. Both indirect IF (IFA), first described by Platt \& Adams (1976) and then refined by Katende et al. (1987), and indirect ELISA (Luckins 1977, Ferenc et al. 1990, Desquesnes 1997a) are useful techniques for epidemiological investigations, especially for the determination of T. vivax distribution. Serological tests available for antibody detection have problems related to specificity due to cross-reaction with other parasites of the same genus, especially in endemic areas where $T$. evansi infections occur (Araújo et al. 1997). The standardization and evaluation of an ELISA with the crude antigen of a Brazilian isolate of T. vivax and seroepidemiological surveys in cattle from PMS and in various micro regions in the PA, Brazil, have been conducted by Madruga et al. (2006). In these studies, the sensitivity and specificity were $97.6 \%$ and $96.9 \%$, respectively. In the evaluation of cross-reactions, three calves inoculated with $T$. evansi trypimastigote blood forms showed optical densities under the cut-off during the whole experimental period (except one at $45 \mathrm{dpi}$ ). The first serological survey of Pantanal and PA showed that T. vivax is widespread, although regions within both areas have significantly different prevalences. Therefore, this Tv-ELISA-Ab may be a more appropriate test for epidemiological surveys.

However, indirect ELISAs have been more widely investigated, since a greater number of samples can be analyzed thanks to the automation of some steps. After the process was first described by Luckins (1977), several indirect ELISAs were developed for the detection of anti-T. vivax antibodies in samples of bovine serum using crude antigen preparations or purified antigen fractions (Greiner et al. 1997, Hopkins et al. 1998, Desquesnes \& Gardiner 1993, Desquesnes 1997a, Rebeski et al. 2001). Luckins (1977), in developing an ELISA for antibody diagnosis in zebu cattle experimentally infected with T. vivax, found the assay failed to differentiate T. brucei, T. vivax, and T. congolense infection. No cross-reaction 
was observed, however, between antigens from sera of animals infected with Trypanosoma theileri, Theileria parva, Theileria mutans, Theileria annulata, Babesia divergens, or Anaplasma marginale.

An ELISA for the detection of IgG-isotype immunoglobulins was developed and compared with IFA. The results demonstrated the absence of cross-reaction with sera of cattle infected with $T$. theileri, and low and moderate levels of cross-reaction with sera of cattle infected with $T$. brucei and T. evansi, respectively (Ferenc et al. 1990). Studies carried out in cattle or sheep have shown that cross reactions between $T$. evansi and T. vivax can be used for the detection of T. vivax infections with the use of $T$. evansi antigens in a heterologous test (Desquesnes et al. 2001). Later, a VSG responsible for cross reaction was identified (Uzcanza et al. 2004).

Other more refined diagnostic techniques have been applied to study T. vivax in South America, such as isoenzyme analysis (Dirie et al. 1993b) and molecular techniques based on nucleic acids (Desquesnes \& Tresse 1996b). Evaluated on a South American T. vivax isolate (Desquesnes \& Tresse 1996b), PCR yielded excellent results, as compared with other diagnostic techniques. Molecular methods, however, are not satisfactory for largescale use in the field (Dwinger \& Hall 2000), as they require well-equipped laboratories, well-trained staff, and costly reagents, some of which are carcinogenic.

In its various stages, trypanosomiasis due to $T$. vivax resembles a number of other disease conditions, and it frequently occurs at the same time as other infections. In the acute febrile stage, trypanosomiasis must be differentiated from redwater (babesiosis), anaplasmosis, and even East Coast fever in Africa. Acute trypanosomiasis rarely produces icterus and is not accompanied by hemoglobinuria. These features and parasitological findings differentiate trypanosomiasis from redwater. These two infections, however, may be concurrent. Similarly, anaplasmosis can occur in trypanosome-infected cattle. On its own, anaplasmosis often produces icterus, as well as fever and anemia; there may also be enlargement of lymph glands. Differentiation relies on the detection of parasites in blood smears. Carcasses of animals that have succumbed to trypanosomiasis are often edematous and anemic. Chronic trypanosomiasis is an afebrile disease of which anemia, emaciation, and lymph node enlargement are common symptoms. It is important to differentiate this disease from malnutrition and helminthosis. In neither of these conditions is lymph node enlargement found. The detection of helminth eggs in feces is a useful adjunct to the diagnosis of helminthosis, but the absence of eggs in fecal samples taken from cattle with chronic fasciolosis, and the occurrence of anemia and subcutaneous edema, can make differential diagnosis difficult. In cases of malnutrition, the degree of anemia is rarely as extensive or severe at the herd scale as it is with trypanosomiasis, although marked individual variations occur. The late stage of enzootic bovine leukosis is characterized by weight loss and lymph node enlargement, but unlike animals suffering from chronic trypanosomiasis, appetite is diminished and anemia is rarely severe (Connor \& Van den Bossche 2005).
When found in blood smears, T. theileri is easily distinguished from other trypanosomes by its large size. Although it may occur in cattle infected with other species of trypanosomes, careful examination of thin Giemsastained blood smears is more likely to reveal the presence of mixed infections of trypanosomes (Gardiner 1989).

\section{Isolation and purification of blood trypanosomes}

Biochemical, biological, and physical methods are available for the isolation of blood trypanosomes. One of the biochemical methods is ion-exchange chromatography (DEAE-cellulose), described by Lanham \& Godfrey (1970), which is based on differences in electrical charges between erythrocytes and trypanosome cell membranes. This is not an optimal method since parasite production and viability can vary (Grab \& Bwayo 1982), however, it the most widely used parasite separation and antigen preparation for ELISA antibody detection tests (Desquesnes et al. 2005). Unlike some West African stocks, the stocks of $T$. vivax isolated so far in Latin America never grow naturally in rodents. It is thus necessary to produce the antigens by cultivation in sheep or cattle, host species in which separation of parasites and blood cells on DEAE-cellulose is quite difficult and produces inconsistent results. For this reason, some authors proposed a technique based on the use of a Percoll gradient (Ndao et al. 2004) or even the combined used of a gradient and DEAE-cellulose (Gonzalez et al. 2005). However, a rodent adapted strain of $T$. vivax from French Guiana is now available at the Centre International de Recherche Développement de l'Elevage en Zone subhumide, Bobo Dioulasso, Burkina Faso (M Desquesnes unpublished observations).

\section{Treatment and control}

Control of the disease should combine restricted movement of diseased animals, treatment of $T$. vivax infected animals, epidemiological monitoring of the distribution and severity of the disease, and vector elimination or control (Dwinger \& Hall 2000). The satisfactory treatment of trypanosomiasis requires more than a correctly administered trypanocidal drug, and the speed of recovery is largely determined by the plan of nutrition, the amount of exercise during convalescence, and the duration of the disease. Well-rested and well-fed animals recover more rapidly after trypanocidal therapy than do undernourished animals that have to trek long distances to reach pastures and water. However, chronic trypanosomiasis often fails to respond to therapy and ferrokinetic disturbances and accompanying dyshemopoiesis appear to be irreversible. Thus, affected animals remain thin and anemic despite trypanocidal treatment (Kinabo 1993, Van den Bossche et al. 2000). Moreover, since trypanosomiasis is most often an enzootic disease, clinical emergence occurs during seasons unfavorable for cattle with regard to food or water shortages.

Drugs regarded as effective in the treatment of $T$. vivax infection include diminazene diaceturate (Beronal ${ }^{\circledR}, \mathrm{Be}-$ renil $\AA$, and Ganaseg $\AA$ (Whitelaw et al. 1989, Katunguka-Rwakishaya et al. 1997) and isometamidium chloride (Trypamidium ${ }^{\circledR}$ (Peregrine et al. 1987, Desquesnes et al. 1995, Geerts et al. 1997, 2001). 
Trypanocidal drugs will continue to play an important role in the integrated control of trypanosomiasis. They appeal to communal cattle owners because they provide a means for protecting private goods and for achieving impressive results at low costs. Although the low-level usage of these drugs may reduce mortality rates, such usage generally has low impact on animal production. This will be the case particularly in high-challenge areas and where farmers use trypanocides therapeutically rather than prophylactically. The development of trypanosome resistance to trypanocides is a continuous threat to their sustainable use in the control of trypanosomiasis. Even in areas where resistance to trypanocides has not yet been demonstrated, the probability of its development should influence the selection of an appropriate control strategy (Van den Bossche et al. 2000).

The antigenic complexity of trypanosomes has thwarted attempts to develop a vaccine (Nantulya 1986). Although potential immunological targets within the parasite have been identified, no vaccine will be commercially available in the near future, and the greatest hope for the immunological control of animal trypanosomiasis lies in the exploitation of trypanotolerant breeds of livestock (Murray et al. 1990). Trypanotolerance is a general breed characteristic and, as such, some individuals are more tolerant than others (Roelants et al. 1983). Furthermore, the trait is complex, and related to the capacity for anemia resistance, the ability to control parasitemia, and, possibly, the ability to mount a more effective immune response to the trypanosome (Murray et al. 1990). It also appears that while these processes are under genetic control, they are not directly linked to each other. The search for genetic markers has concentrated on the major histocompatibility complex and on leukocyte antigens (Connor \& Van den Bossche 2005).

\section{REFERENCES}

Allsopp BA, Newton SD 1985. Characterization of Trypanosoma vivax by isoenzyme analysis. Int J Parasitol 5: 265-270.

Andrianarivo AG, Muyra P, Opollo MM, Logan-Hemfrey LL 1995. Trypanosoma congolense: comparative effects of primary infection on bone marrow progenitor cells from N'dama and Boran cattle. Exp Parasitol 80: 407-414.

Anosa VO, Isoun TT 1980. Haematological studies on Trypanosoma vivax infection of goats and intact and splenectomized sheep. $J$ Comp Pathol 90: 155-168.

Araújo FR, Madruga CR, Leal CRB, Massuda T, Schenk MA 1997. Desenvolvimento de uma prova de imunoadsorção enzimática (ELISA) para detecção de anticorpos contra Trypanosoma vivax. Rev Bras Parasitol Vet 6: 2.

Ashcroft MT 1957. The polymorphism of Trypanosoma brucei and $T$. rhodesiense, its relation to relapses and remissions of infections in white rats, and the effect of cortisone. Ann Trop Med Parasitol 51: 301-311.

Assoku RKG, Gardiner PR 1989. Detection of antibodies to platelets and erythrocytes during haemorrhagic Trypanosoma vivax infection of Aryshire cattle. Vet Parasitol 31: 199-216.

Authié E, Pobel T 1990. Serun haemolytic complement activity and $\mathrm{C} 3$ levels in bovine trypanosomiasis under natural conditions of challenge early indications of individual susceptibility to disease. Vet Parasitol 35: 43-59.
Batista JS, Riet-Correa F, Teixeira MM, Madruga CR, Simões SD, Maia TF 2007. Trypanosomiasis by Trypanosoma vivax in cattle in the Brazilian semiarid: Description of an outbreak and lesions in the nervous system. Vet Parasitol 143: 174-181.

Bawa EK, Ogwu D, Sekoni VO, Oyedipe EO, Esievo KA, Kambai JE 2000. Effects of Trypanosoma vivax on pregnancy of Yankasa sheep and the results of homidum chloride chemotherapy. Theriogenology 54: 1033-1040.

Betancourt A, Wells AE 1979. Pérdidas económicasnen un brote de tripanosomiasis bovina causado por Trypanosoma vivax. Rev Asoc Columb Med Vet Zoot 3: 6-9.

Betancourt AE, Julio TM 1979. La tecnica de centrifugacion en tubo capilar el diagnostico de infecciones naturales por Trypanosoma sp. Rev ICA Bogota 14: 105-108.

Brener Z 1979. O parasito: Relações hospedeiro-parasito. In Z Brener, $\mathrm{Z}$ Andrade, Trypanosoma cruzi e doença de Chagas, Guanabara Koogan, Rio de Janeiro, p. 1-41.

Camus E, Martrenchar A 1990. Infection expérimentale de zébus guyanais avec Trypanosoma vivax. Rev Elev Med Vet Pays Trop 43: 467-472.

Carougeau M 1929. Tripanosomose bovine à la Martinique. Bull Soc Path Exot 22: 246-247.

Connor RJ, Van den Bossche P 2005. African animal Trypanosomes. In JAW Coetzer, RC Tustin, Infection Diseases of Livestock, 2nd ed., Vol 1, Oxford University Press, Cape Town, p. 251-296.

Cordoves CO, Fernandez C, Garcia AJ, Gonzalez BR 1982. Trypanosoma vivax, Ziemann, 1905. Lista de transmisores mecanicos en Cuba. Rev Cub de Cien Vet 13: 219-221.

Cortez AP, Ventura RM, Rodrigues AC, Batista JS, Paiva F, Añez N, Machado RZ, Gibson WC, Teixeira MM 2006. The taxonomic and phylogenetic relationships of Trypanosoma vivax from South America and Africa. Parasitol 133: 159-169.

Curasson G 1943. Traité de protozoologie vétérinaire et comparée. I. trypanosomes. Vigot Fréres, Paris, $445 \mathrm{pp}$.

Dávila AMR, Ramirez L, Silva RAMS 1997. Morphological and biometrical differences among Trypanosoma vivax isolates from Brazil and Bolivia. Mem Inst Oswaldo Cruz 92: 357-358.

De Baetselier PD, Namangala B, Noel W, Brys L, Pays E, Beschin A 2001. Alternative versus classical macrophage activation during experimental African Trypanosomiasis. Int J Parasitol 31: 575-587.

Desquesnes M 1995. Evaluation of three antigen detection tests (monoclonal trapping ELISA) for African trypanosomes, with an isolate of T. vivax from French Guyana. Ann N Y Acad Sci 791: 172-184.

Desquesnes M 1997a. International and regional standardization of immunoenzyme tests: methods, concerns and limitations. Rev Sci Tech 16: 809-823.

Desquesnes M 1997b. Les trypanosomes du bétail en Amérique Latine, étude spéciale dans le Plateau des Guyanes, PhD Thesis, Université de Lille II, 409 pp.

Desquesnes M 2004. Livestock trypanosomoses and their vectors in Latin America, OIE \& CIRAD, Paris, 190 pp.

Desquesnes M, Bengaly Z, Millogo L, Meme Y, Sakande H 2001. The analysis of the cross-reactions occurring in antibody-ELISA for the detection of trypanosomes can improve identification of the parasite species involved. Ann Trop Med Parasitol 95: 141-155.

Desquesnes M, De La Rocque S, Peregrine AS 1995. French Guyana stock of Trypanosoma vivax resistant to diminazine aceturate but sensitive to isometamidium chloride. Acta Trop 60: 133-136. 
Desquesnes M, Dia ML 2003. Trypanosoma vivax: Mechanical transmission in cattle by one of the most common African tabanids, Atylotus agrestis. Exp Parasitol 103: 35.

Desquesnes M, Dia ML 2004. Mechanical transmission of Trypanosoma vivax in cattle by the African tabanid Atylotus fuscipes. Vet Parasitol 119: 9-19.

Desquesnes M, Dia ML, Acapovi G, Yoni W 2005. Les vecteurs mécaniques des trypanosomoses animals. Généralités, morphologie, biologie, impacts et contrôle. Identification des espèces les plus abondantes en Afrique de l'Ouest, Edition CIRDES, Imp. de l'Avenir, Ouagadougou, Burkina Faso, 70 pp.

Desquesnes M, Gardiner PR 1993. Épidémiologie de la trypanosome bovine (Trypanosoma vivax) en Guyane Française. Rev Elev Med Vet Pays Trop 46: 463-470.

Desquesnes M, Tresse L 1996a Evaluation de la sensibilité du test de Woo pour la détection de Trypanosoma vivax. Rev Elev Med Vet Pays Trop 49: 315-321.

Desquesnes M, Tresse L 1996b. Evaluation de la sensibilité de la PCR pour la détection de I'ADN de Trypanosoma vivax selon divers modes de préparation des échantillons sanguins. Rev Elev Med Vet Pays Trop 49: 322-327.

Dirie MF, Murphy NB, Gardiner PR 1993a. DNA fingerprinting of Trypanosoma vivax isolates rapidly identifies intraspecific relationships. J Euk Microbiol 40: 132-134.

Dirie MF, Otte MJ, Thatthi R, Gardiner PR 1993b. Comparative studies of Trypanosoma (Duttonella) vivax isolates from Colombia. Parasitology 106: 21-29.

Dwinger RH, Hall MJR 2000. Trypanosomiasis due to Trypanosoma vivax in ruminants in Latin America - a review. In 51-58 International Atomic Energy Agency, Vienna, Austria (eds), Animal Trypanosomiasis: Diagnosis and Epidemiology, Backhuys Publishers, The Netherlands, p. 50-55.

Emery DL, Akol GW, Murray M, Morrison WI, Moloo SK 1980. The chancre: early events in the pathogenesis of African trypanosomiasis in domestic livestock. In H Van Den Bossche (ed.), The host invader interplay, Elsevier, Amsterdam, p. 345-356.

Esievo KAN, Jaye A, Andrews JN 1990. Electrophoresis of bovine erythrocyte sialic acids: existence of additional bands in trypanotolerant N'Dama cattle. J Comp Pathol 102: 357-361.

Esievo KAN, Saror DI 1983. Leukocyte response in experimental Trypanosoma vivax infection in cattle. J Comp Pathol 93: 165-169.

Esievo KAN, Saror DI, Kolo MN, Eduvie LO 1986. Erythrocytes surface sialic acid in N'Dama and Zebu cattle. J Comp Pathol 96: 95-99.

Esievo KAN, Saror DI, LLemobade AA, Hallway MH 1982. Variation in erythrocyte surface and free serum sialic acid concentrations during experimental Trypanosoma vivax infections in cattle. Res Vet Sci 32: 1-5.

Fabre H, Bernard M 1926. Sur un nouveau de trypanosomiasis bovine observé à la Guadaloupe. Bull Soc Path Exot 19: 435-437.

Ferenc SA, Stopinski V, Cortney CH 1990. The development of an enzyme-linked immunosorbent assay for Trypanosoma vivax and its use in a seroepidemiological survey of the Eastern Carribean basin. Int J Parasitol 20: 51-56.

Fernandez AJ 1931. Tripanosomiasis de los bovídeos de Venezuela. Gac Med Caracas 38: 17-21.

Fiasson R, Mayer M, Pifano F 1948. Le cariacou (Odoceileus gymnotis) porteur de Trypanosoma vivax en Venezuela. Bull Soc Path Exot 41: 206-208.

Flynn JN, Sileghem M 1991. The role of macrophage in induction of immunosuppression in Trypanosoma congolense infected cattle. Immunology 74: 310-316.

Gardiner PR 1989. Recent studies of the biology of Trypanosoma vivax. Adv Parasitol 28: 229-317.

Geerts S, Holmes PH, Eisler MC, Diall O 2001. African bovine trypanosomiasis: the problem of drug resistance. Trends Parasitol 17: $25-28$.

Geerts S, Kageruka P, De Deken R, Brandt JR, Kazadi JM, Diarra B, Eisler MC, Lemmouchi Y, Schacht E, Holmes PH 1997. Prophylactic effects of isometamidium and ethidium-sustained release devices against Trypanosoma congolense in cattle. Acta Trop 65: 23-31.

Gibson W 1995. The significance of genetic exchanges in trypanosomes. Parasitol Today 11: 465-468.

Gonzalez LE, Garcia JA, Nunez C, Perrone TM, Gonzalez-Baradat B, Gonzatti MI, Reyna-Bello A 2005. Trypanosoma vivax: a novel method for purification from experimentally infected sheep blood. Exp Parasitol 111: 126-129.

Grab DJ, Bwayo JJ 1982. Isopycnic isolation of African trypanossomes on percoll gradients formed in situ. Acta Trop 39: 363-366.

Greiner M, Kumar S, Kyeswa C 1997. Evaluation and comparison of antibody ELISAs for serodiagnosis of bovine Trypanosomiasis. Vet Parasitol 31: 197-205.

Hoare CA 1938. Morphological and taxonomic studies on mammalian trypanosomes. V. The diagnostic value of the kinetoplast. Trans $R$ Soc Trop Med Hyg 32: 333.

Hoare CA 1972. The trypanosomes of mammals: a zoological monograph, Blackwell, Oxford, 749 pp.

Hoof L, Van Henrard C, Peel E 1948. Quelques observations sur les trypanosomes del grands mammifères au Congo Belge. Acta Trop 5: 327.

Hopkins JS, Chitambo H, Machila N, Luckins AG, Rae PF, Van den Bossche P, Eisler MC 1998. Adaptation and validation of antibody-ELISA using dried blood spots on filter paper for epidemiological surveys of tsetse-transmitted Trypanosomiasis in cattle. Prev Vet Med 37: 91-99.

ICA - Instituto Colombiano Agropecuario 1980. Las enfermedades de los animales en Colombia: situacion por regiones naturales, ICA, Bogotá, 237 pp.

ILRAD - International Laboratory for Research on Animal Diseases 1989. Annual report of the international laboraratory for reseach on animal diseases, Nairobi, Kenya, 24-66 pp.

Johnson CM 1941. Bovine trypanosomiasis in Panama. Am J Trop Med 21: 289-297.

Katende JM, Musoke AJ, Nantulya VM, Goddeeris BM 1987. A new method for fixation and preservation of trypanosomal antigens for use in the indirect immunofluorescence antibody test for diagnosis of bovine trypanosomiasis. Trop Med Parasitol 38: 41-44.

Katunguka-Rwakishaya E, Murray M, Holmes PH 1997 Susceptibility of three breeds of Ugandan goats to experimental infection with Trypanosoma congolense. Trop Anim Health Prod 29: 7-14.

Kimeto BA, Mugera GM, Nyaga PN 1990. Haemorrhagic pancarditis in cattle infected with Trypanosoma vivax. Vet Parasitol 34: 295-301.

Kinabo LDB 1993. Pharmacology of existing drugs for animal trypanosomiasis. Acta Trop 54: 169-183.

Lanham SM, Godfrey DG 1970. Isolation of salivariam trypanosomes from man and other mammals using DEAE-Cellulose. Exp Parasitol 28: 251-534.

Lerger M, Viene M 1919. Epizoootie à trypanosomes ches les boidés de la Guyiane Francaise. Bull Soc Pathol Exot 12: 258-266. 
Levine ND 1973. The hemoflagellates. In ND Levine, Protozoan parasites of domestic animals and of man, 2nd ed., Burgess Publishing, Minneapolis, p. 36-78.

Losos GJ, Ikede BO 1972. Review of pathology of disease in domestic and laboratory animals caused by Trypanosoma congolense, T. vivax, $T$. brucei, T. rhodesiense and T. gambiense. Vet Pathol 9: 1-71.

Luckins AG 1977. Detection of antibodies in trypanosome-infected cattle by means of a microplate enzyme-linked immunosorbent assay. Trop Anim Health Prod 9: 53-62.

MacAskill JA, Holmes PH, Whitelaw DD, Me Connell L, Jennings FW, Urquhart GM 1980. lmmunological clearence of Se-labeled Trypanosoma brucei in mice. II. Mechanisms in immune animals. Immunology 40: 629-635.

Madruga CR, Araújo FR, Cavalcante-Goes G, Martins C, Pfeifer IB, Ribeiro LR 2006. The development of an enzyme-linked immunosorbent assay for Trypanosoma vivax antibodies and its use in epidemiological surveys. Mem Inst Oswaldo Cruz 101: 801-807.

Madruga CR, Morzaria S, Majiwa P 1999. Caracterização genética do Trypanossoma vivax no Pantanal do estado de Mato Grosso e o diagnóstico diferencial da infecção por Trypanosoma evansi pela reação em cadeia da polimerase (PCR). Pesquisa em Andamento. Embrapa Gado de Corte 49: 1-5. Available at http://www.cnpgc. embrapa.br/publicacoes/pa/pa49.html.

Maillard N, Maillard JC 1998. Historique du peuplement bovin et de l'introduction de la tique Amblyomma variegatum dans les îles françaises des Antilles: synthèse bibliographique. Ethnozootechnie 61: 19-36.

Majiwa PAO, Ole-MoiYoi OK, Nantulya VM 1993. New techniques for diagnosis of the African trypanosomes. Ag Biotech 5: 115-120.

Meléndez RD, Forlano M, Figueiroa W 1993. Perinatal infection with Trypanosoma vivax in a calf in Venezuela. J Parasitol 79: 293-294.

Molyneux DH 1975. Diagnostic methods in animal trypanosomiases. Vet Parasitol 1: 5-17.

Molyneux DH, Ashford RW 1983. The parasites. In DH Molyneux, RW Ashford, The biology of Trypanosoma and Leishmania, parasites of man and domestic animals, 1st ed., Taylor \& Francis, London, p. 3-62.

Morzaria S, Masake R, Rowland J, Musoke T (eds) 1996. Antigen ELISAs for trypanosomes. Eevaluation of the performance. International Livestock Research Institute, Nairobi, Kenya, 129 pp.

Mulla AF, Rickman LR 1988. How do African game animals control trypanosome infections? Parasitol Today 4: 352-354

Murray M, Clifford DJ, Mcintyre WIM 1979. Diagnosis of African trypanosomiasis in the bovine. Trans R Soc Trop Med Hyg 73: $120-121$.

Murray M, Dexter TM 1988. Anaemia in bovine African trypanosomiasis: a review. Acta Trop 45: 389-432.

Murray M, Morrison WI, Whitelaw DD 1982. Host susceptibility to African trypanosomiasis: trypanotolerance. Adv Parasitol 21: 1-68.

Murray M, Trail JCM, D'Ieteren GDM 1990. Tripanotolerance in cattle and prospects for the control of trypanosomiasis by selective breeding. Rev Sci Tech 9: 369-386.

Mwongela GN, Kovatch RM, Frazil MA 1981. Acute Trypanosoma vivax infection in dairy cattle in Coast Province, Kenya. Trop Anim Health Prod 13: 63-69.

Nantulya VM 1986. Immunological approaches to the control of animal trypanosomiasis. Parasitol Today 2: 168-173.

Nantulya VM, Lindqvist KJ 1989. Antigen-detection enzyme immunoassays for the diagnosis of Trypanosoma vivax, T. congolense and
T. brucei infections in cattle. Trop Med Parasitol 40: 267-272.

Nantulya VM, Musoke AJ, Rurangirwa FR, Barbet AF, Ngaira J, Katende JM 1982. Immune depression in African trypanosomiasis: the role of antigenic competition. Clin Exp Immunol 47: 234-241.

Ndao M, Magnus E, Buscher P, Geerts S 2004. Trypanosoma vivax: a simplified protocol for in vivo growth, isolation and cryopreservation. Parasite 11: 103-106.

Nielsen K, Sheppard J, Holmes W, Tizard I 1978. Experimental bovine trypanosomiasis. Changes in serum immunoglobulins, complement and complement components in infected animals. Immunology 35: 817-826.

Ogwu D, Nuru S 1981. Transplacental transmission of trypanosomes in animals and man. Vet Bull 51: 381-384.

Osório ALAR 2002. Polimorfismo genético de Trypanosoma (Duttonella) vivax no Pantanal brasileiro e caracterização antigênica e ultra-estrutural de suas frações subcelulares, $\mathrm{PhD}$ Thesis, Fiocruz, Rio de Janeiro, 105 pp.

Otte MJ, Abuabara JY 1991. Transmission of South American Trypanosoma vivax by the neotropical horsefly Tabanus nebulosus. Acta Trop 49: 73-76.

Otte MJ, Abuabara JY, Wells EA 1994. Trypanosoma vivax in Colombia: epidemiology and production losses. Trop Anim Health Prod 26: 146-156.

Paiva F, Lemos RAA, Oshiro ET, Salvador SC, Nakazato L 1997. Ocorrência de Trypanosoma vivax em bovinos no Estado de Mato Grosso do Sul. Rev Bras Parasitol Vet 6 (Supp. I): 349.

Paling RW, Moloo SK, Scott JR, McOdimba FA, Logan-Henfrey LL, Murray M. Williams DJL 1991. Susceptibility of N'Dama and Boran cattle to tsé-tsé-transmitted primary and rechallenge infections with a homologous serodeme of Trypanosoma congolense. Parasite Immunol 13: 413-425.

Peregrine AS, Moloo SK, Whitelaw DD 1987. Therapeutic and prophylactic activity of isometamidium chloride in Boran cattle agains Trypanosoma vivax transmitted by Glossina morsitans centralis. Res Vet Sci 43: 268-270.

Pereira LJ, Abreu ACVV 1979. Ocorrência de tripanossomas em bovinos e ovinos da região amazônica. Pesqui Agropecu Bras 13: 17-21.

Plata R 1931a. Los portadores latentes en la tripanosomiasis bovina. Rev Med Vet Bogota 3: 213-217.

Plata R 1931b. Nota preliminar sobre una trypanosomiais del ganado vacuno en Bolívar. Rev Med Vet Bogota 3: 77-79.

Platt KB, Adams LG 1976. Evaluation of the indirect fluorescent antibody test for detecting Trypanosoma vivax in South American cattle. Res Vet Sci 21: 53-58.

Raymond HL 1990. Tabanus importunus, vecteur mécanique experimental de Trypanosoma vivax en Guyane Française. Ann Parasitol Hum Comp 65: 44-46.

Rebeski DE, Winger EM, Ouma JO, Kong-Pages S, Buscher P, Sanogo Y, Dwinger RH, Crowther JR 2001. Charting methods to monitor the operational performance of ELISA method for the detection of antibodies against trypanosomes. Vet Parasitol 96: 11-50.

Roberts LW, Wellde BT, Reardon MJ, Onyango FK 1989. Mechanical transmission of Trypanosoma brucei rhodesiense by Glossina morsitans morsitans (Diptera: Glossinidae). Ann Trop Med Parasitol 83: 127-131.

Roeder PL, Scott JM, Pegram RG 1984. Acute Trypanosoma vivax infection of Ethiopian cattle in the apparent absence of tsé-tsé. Trop Anim Health Prod 16: 141-147.

Roelants GE, Tamboura I, Sidiki DB, Bassinga A, Pinder M 1983. 
Tripanotolerance: An individual not a breed character. Acta Trop 40: 99-104.

Ruiz-Martinez C 1971. Les trypanosomiases au Venezuela. Progrès obtenus dans la lutte et la prophylaxie de la maladie. Bull Off Int Epizoot 76: 275-89.

Saror DI 1979. Classification of the anaemia of bovine trypanosomiasis. Vet Rec 105: 96-98

Schenk, Maria AM, Mendonça CL, Madruga CR, Kohayagawa A, Araújo FR 2001. Avaliação clínico-laboratorial de bovinos Nelore infectados experimentalmente com Trypanosoma vivax. Pesq Vet Bras 21: 157-161.

Seidl A, Dávila AMR, Silva RAMS 1999. Estimated financial impact of Trypanosoma vivax on the Brazilian Pantanal and Bolivian lowlands. Mem Inst Oswaldo Cruz 94: 269-272.

Sekoni VO 1993. Elevated sperm morphological abnormalities of Yankasa rams consequent to Trypanosoma vivax infection. Anim Reprod Sci 31: 243-248.

Sekoni VO, Saror DI, Njoku CO, Kumi-Diaka J 1990. Elevation of morphological abnormalites of spermatozoa in the semen of Zebu bulls consequent to Trypanosoma vivax and Trypanosoma congolense infections. Theriogenology 33: 925-936.

Shakibaei M, Frevert U 1992. Cell surface interactions between Trypanosoma congolense and macrophages during phagocytosis in vitro. J Protozool 39: 224-235.

Shaw JJ, Lainson R 1972. Trypanosoma vivax in Brasil. Anim Trop Med Parasitol 66: 25-32.

Sileghem M, Darji A, De Baetselier P 1991. In vitro simulation of immunosuppression caused by Trypanosoma brucei. Immunology 73: $246-248$.

Sileghem M, Flynn J.N, Darji A, De Baetselier P, Naessens J 1994a. African trypanosomiasis. In F Kierszenbaum (ed.), Parasite infections and the Immune System, Academic Press, San Diego, p. 1-51.

Sileghem M, Flynn JN, Logan-Henfrey L, Ellis J 1994b. Tumor necrosis factor production by monocytes from cattle infected with Trypanosoma (Duttonella) vivax and Trypanosoma (Nannomonas) congolense: possible association with severity of anaemia associated with the disease. Parasite lmmunol 16: 51-54.

Silva RAMS, Da Silva JA, Schneider RC, De Freitas J, Mesquita D, Mesquita T, Ramirez L, Dávila AMR, Pereira MEB 1996. Outbreak of trypanosomiasis due to Trypanosoma vivax (Ziemann, 1905) in bovines of the Pantanal, Brazil. Mem Inst Oswaldo Cruz 91: 561-562.

Silva RAMS, Ramirez L, Souza SS, Ortiz AG, Pereira SR, Dávila AMR 1999. Hematology of natural bovine Trypanosomiasis in the Brazilian Pantanal and Bolivian wetlands. Vet Parasitol 85: 87-93.

Silva RAMS, Silva JA, Shneider RC, Freitas J, Mesquita T, Ramirez L, Dávila AMR, Pereira MEB 1995. Bovine Trypanosomiasis due to Trypanosoma vivax in the Northern subregion of Pantanal, Brasil. Trynews 4: 1-2.

Souza MC 1980. Estudo de infecções experimentais por Trypanosoma (Duttonella) vivax Ziemann 1905, em animais domésticos, MSc Thesis, Universidade Federal Rural do Rio de Janeiro, Seropédica, $110 \mathrm{pp}$.

Tabel H, Losos GJ, Maxie MG 1980. Experimental bovine trypanosomiasis (Trypanosoma vivax and T. congolense). II. Serum levels of total protein, albumin, hemolytic complement, and complement component C3. Tropenmed Parasitol 31: 99-104.

Taylor KA 1998. Immune responses of cattle to African trypanosomes: protective or pathogenic. Int J Parasitol 28: 219-240.

Taylor KA, Lutje V, Kennedy D, Authié E, Boulangé A, Logan-Hen- frey L, Gichuki B, Gettinbly G 1996a. Trypanosoma congolense: B-lymphocyte responses differ between trypanotolerant and trypanosusceptible cattle. Exp Parasitol 83: 106-116.

Taylor KA, Lutje V, Mertens B 1996b. Nitric oxide synthesis is depressed in Bos indicus cattle infected with Trypanosoma congolense and T. vivax and does not mediate T cell suppression. Infect Immun 64: 4115-4122.

Taylor KA, Mertens B 1999. Immune response of catte infected with African trypanosomes. Mem Inst Oswaldo Cruz 94: 239-244.

Tejera E 1920. Trypanosomiases animales au Venezuela. Bull Soc Path Exot 13: 297-305.

Tuntasuvan D, Sarataphan N, Nishikawa H 1997. Cerebral trypanosomiasis in native cattle. Vet Parasitol 31: 357-363

Uzcanga GL, Perrone T, Noda JA, Perez-Pazos J, Medina R, Hoebeke J, Bubis J 2004. Variant surface glycoprotein from Trypanosoma evansi is partially responsible for the cross-reaction between Trypanosoma evansi and Trypanosoma vivax. Biochemistry 43: 595-606.

Valli VEO, Forsberg CM 1979. The pathogenesis of Trypanosoma congolense. Quantitative histological changes. Vet Pathol 16: 334-368.

Van den Bossche P, Shumba W, Makhambera P 2000. The distribution and epidemiology of bovine trypasonomosis in Malawi. Vet Parasitol 88: 163-176.

Van den Ingh TS, Neijs-Bakker MH 1979. Pancarditis in Trypanosoma vivax infection in cattle. Tropenmed Parasitol 30: 239-243.

Ventura RM, Paiva F, Silva RAMS,Takeda GF, Buck GA, Teixeira MMG 2001. Trypanosoma vivax: characterization of the splicedleader gene of a Brazilian stock and species-specific detection by PCR amplification of an intergenic spacer sequence. Exp Parasitol 99: 37-48

Vickerman K 1962. The mechanism of cyclical development in trypanosomes of the Trypanosoma brucei sub-group: a hypothesis based on ultrastrutural observations. Trans R Soc Trop Med Hyg 56: 487-495.

Virviescas F 1932. La lucha contra la tripanosomiasis bovina en la Costa Atlantica. Rev Med Vet Bogota 4: 315-26.

Vohradsky F 1971. Signes cliniques, taux d'infestation journaliers, modifications hématologiques et pathomorphologiques sur du bétail infesté. Rev Elev Med Vet Pays Trop 24: 251-263.

Wells EA 1972. The importance of mechanical transmission in the epidemiology of nagana. Trop Anim Health Prod 4: 74-88.

Wells EA, Betancourt A, Ramirez LE 1982. Trypanosoma vivax in Colombia epidemiology and economic impacto. FAO-World Animal 43: 17-23.

Whitelaw DD, Bell IR, Holmes PH 1989. Immunological clearance of Se-labeled Trypanosoma brucei in goats. Acta Trop 46: 101-106.

Whitelaw DD, Gardiner PR, Murray M 1988. Extravascular foci of Trypanosoma vivax in goats: the central nervous system and aqueous humor of the eye as potential sources of relapse infections after chemotherapy. Parasitology 7: 51-61.

Williams DJ, Logan-Henfrey LL, Authié E, Seely C, McOdimba F 1992. Experimental infection with a haemorrhage-causing Trypanosoma vivax in N'Dama and Boran cattle. Scand J Immunol 36 (Suppl. I): 34-36.

Williams DJ, Taylor KA, Newson J, Gichuki B 1996. The role of antivariable surface glycoprotein antibody responses in bovine trypanotolerance. Parasite lmmunol 18: 209- 218.

Woo PTK 1970. The haematocrit centrifuge technique for the diagnosis of African Trypanosomiasis. Acta Trop 27: 384-386. 